\title{
What is the impact of socio-economic inequalities on the use of mental health services?
}

\author{
FRANCESCO AMADDEO and JULIA JONES
}

\begin{abstract}
Amartya Sen, who received the Nobel Prize for Economics, has demonstrated that the incidence of deprivation, in terms of capability, can be surprisingly high even in the most developed countries of the world. The study of socio-economic inequalities, in relation to the utilisation of health services, is a priority for epidemiological research. Socio-economic status (SES) has no universal definition. Within the international research literature, SES has been related to social class, social position, occupational status, educational attainment, income, wealth and standard of living. Existing research studies have shown that people from a more deprived social background, with a lower SES, are more likely to have a higher psychiatric morbidity. Many studies show that SES influences psychiatric services utilization, however the real factors linking SES and mental health services utilisation remain unclear. In this editorial we discuss what is currently known about the relationship between SES and the use of mental health services. We also make an argument for why we believe there is still much to uncover in this field, to understand fully how individuals are influenced by their personal socio-economic status, or the neighbourhood in which they live, in terms of their use of mental health services. Further research in this area will help clarify what interventions are required to provide greater equality in access to mental health services.
\end{abstract}

\section{INTRODUCTION}

The study of the relationship between social conditions and health services utilisation is of crucial importance for all those interested in mental health services evaluation at different spatial levels. As the Nobel Prize winner, Amartya Sen (1992) has demonstrated, the incidence of deprivation, in terms of capability,' can be surprisingly high even in the most developed countries of the world. For this reason, interest in this topic has grown among mental health researchers, aware that relative deprivation in their own countries has an impact upon the utilization of mental health services. The results of research studies in this field will enable us to develop the principal tools required to develop and maintain modern, effective and safe mental health services that can be accessed and used by all those who need them.

A couple of years ago we were part of a research team that published a case register study that posed the question 'Does socio-economic status affect the use of community-based psychiatric services?' (Tello et al., 2005). In that article we endeavoured to demonstrate, by describing a research study conducted in South Verona (Italy), that socio-economic status does indeed affect the use of community-based psychiatric services. In this editorial, we will examine further the theory that people from a more deprived social background, with a lower socio-economic status (SES), are not only more likely to have a higher psychiatric morbidity but that they also use services more frequently than people from a more affluent background. We will also examine the notion that individuals from a more deprived social background may sometimes experience greater difficulties in accessing mental health services, such as being referred or physically getting to a hospital or community-based mental health facility, particularly if individuals live some distance away.
Address for correspondence: Professor F. Amaddeo, Section of Psychiatry and Clinical Psychology, Department of Medicine and Public Health, University of Verona, Policlinico G.B. Rossi, P.le L. Scuro 10, 37134 Verona (Italy).

Fax: +39-045-812.4889

E-mail: francesco.amaddeo@univr.it

Declaration of Interest: none.

\footnotetext{
' A. Sen proposed to replace the concept of utility with the concept of capability in assessing inequalities. Capability is defined by Sen as: "The capability of a person reflects the alternative combination of functionings the person can achieve, and from which he or she can choose one collection. The approach is based on a view of living as a combination of various «doings and beings», with quality of life to be assessed in terms of the capability to achieve valuable functionings".
} 


\section{WHY ARE WE INTERESTED IN SOCIO-ECONOMIC STATUS?}

Socio-economic status (SES) is a complex concept with no universal definition (Dohrenwend, 1990). When one looks at the international research literature on SES it is evident that it is related to social class, social position, occupational status, educational attainment, income, wealth and standard of living (Bonizzato \& Tello, 2003). It also appears that there are different ways of measuring SES, something that is often country-specific and related to the different questions asked in national population censuses. For example, a number of well known censusbased SES indices in the UK, such as those developed by Jarman (1983) and Townsend (1987) include the census variable 'car ownership' as an indicator of SES. However, in other countries, such as in Italy, this question is not asked in a national census. Accordingly, many SES indices are country or even place-specific. For example: the Carstairs scores developed in Scotland (Carstairs \& Morris, 1991); a community-based index created in Turin, Italy (Cadum et al., 1999); the Rome SES index (Michelozzi et al., 1999); the deprivation index of Tuscany Region in Italy (Regione Toscana, 2001); and from Spain the Barcelona index (Benach et al., 2001).

Regarding the relationship between SES and mental health, existing studies demonstrate that people from a more deprived social background, with a lower socioeconomic status (SES), are more likely to have a higher psychiatric morbidity (Bijl et al., 1998; Glover et al., 1999; Bonizzato \& Tello, 2003). We also know that socioeconomic deprivation is particularly associated with rates of depression and anxiety disorders (Dohrenwend, 1990; Ostler et al., 2001; World Health Organisation, 2001; Weich et al., 2001).

As discussed by various authors, the culmination of research findings over the years suggest two possible classical explanations for the concentration of mentally ill people in particular localities: social causation and social selection. Social causation suggests that a lower individual SES, or lower SES in the community where people live (i.e. ecological), may produce or contribute to mental illness because of deprivation, poor living and housing standards and a lack of social cohesion. The second explanation supports the hypothesis that the relationship between SES and mental disorders results from a drift of mentally ill people to lower SES conditions, with people's social-economic status worsening as their mental health declines. More deprived areas also offer more affordable accommodation and frequently there will already be specialist mental health care services being provided in the neighbourhood, which may provide a 'pull' factor for mentally ill people. Recently studies have been published that highlight the importance of urbanicity as a risk factor for schizophrenia (Amaddeo \& Tansella, 2006; McGrath \& Scott, 2006; Pedersen \& Mortensen, 2006; Spauwen \& van Os, 2006), and the correlation between urbanicity and socio-economic conditions remains ambiguous. For example, it is possible that some influential factors may be hidden beneath the concept of urbanicity, factors such as population density or concentration of ethnic minority groups, and a high incidence of infective diseases could also be related with poorer living conditions found in some parts of urban areas.

\section{HOW SES AFFECTS MENTAL HEALTH SERVICE USE}

The association between socio-economic characteristics and rates of psychiatric service utilisation is also well established, with a number of studies demonstrating that psychiatric service use is more prevalent in geographical areas characterised by social deprivation, particularly in urban environments (Faris \& Dunham, 1939; Jarman et al., 1992; Thornicroft, 1991), although studies from the UK, USA and Italy show that the strength of association varies according to psychiatric diagnosis (Tansella et al., 1993; Harrison et al., 1995; Boardman et al., 1997; Koppel \& McGuffin, 1999). A previous study, conducted in South Verona, Northern Italy, has highlighted the fact that ecological characteristics, derived from district level census data, can be good predictors of psychiatric service use by patients with a diagnosis of psychosis, but not by people suffering from a neurotic and somatoform disorder (Tansella et al., 1993; Thornicroft et al., 1993). Using 1981 Census data, this study identified four socio-demographic variables that were associated with psychiatric service utilisation: living alone; unemployment; the percentage of the total population who are dependent (dependent ratio); and the percentage of people who are separated, divorced or widowed.

In our latest study (Tello et al., 2005), using 1991 Census data at the census-block level, we found that the annual treated prevalence was two times greater for those living in more deprived areas compared with those in affluent areas; only 1-year treated incidence rates, length of stay in hospital, rates of first-ever admission to hospital and mean number of contacts with day care were equally distributed between SES groups. In other words, while no association between SES and psychiatric service 
use emerged for new patients, those patients who had a previous psychiatric history and were living in more deprived areas made a greater use of psychiatric services.

These findings seem to suggest that SES has a potential to worsen among those suffering from psychiatric illnesses (social selection), whilst the equal distribution of incidence rates by SES seems to exclude the possibility that SES is a contributory casual factor to becoming mentally unwell. However, important theoretical questions regarding the effects of social conditions on mental illness and vice versa, cannot be answered by case register studies, rather they require population studies. Nevertheless, it is important to reflect upon the findings that two service use variables, length of stay in hospital and number of day contacts, were not significantly associated with SES group. This finding could be because of the relatively small capacity of hospital beds (which determines, in most cases, a relatively short length of stay and a relatively high turnover of patients) and also the small number of day care places available. Only when mental health care is easy accessible to all and free of charge, can the quantity and type of service consumption be regarded as an indicator of the level of severity of the mental illness.

\section{ACCESSIBILITY AND UTILISATION}

Equitable access to health care is a guiding principle of health care services in countries with a National Health Service, such as the U.K. and Italy, with the aim of national health services to provide care that is based on need alone, irrespective of where people live. Accessibility involves more than simply physical distance, with other related factors also important, such as the cost of a journey, availability of transportation, time constraints, psychological barriers of the journey, social and cultural factors and so on (Lovett et al., 2002; Haynes et al., 1999; Blazer et al., 1995). Many of these factors will be determined by an individual's socio-economic status, for example whether they are a car owner and can drive easily to a hospital or health centre. An individual with a lower SES may not own a car, and will then have to rely on public transport, with transport routes that may or may not pass nearby a static health care facility.

As discussed in detail in Sarah Curtis's editorial in this issue (Curtis, 2007), we know that the relationship between distance from hospital and service use is complex, with continued debate in the international research literature regarding the importance of proximity to static facilities as well as the best method to measure distance between where service users live and the health services they use. There is some evidence within the general health care literature to suggest that geographical inequalities do exist, with individuals living further away from static health services using those services less than those individuals who live closer to them (NHS Centre for Reviews and Dissemination, 1997; Joseph \& Philips, 1984). However, there is a paucity of studies that consider accessibility and utilization of mental health services, particularly services that are community-based, rather than in hospitals. Furthermore, it needs to be acknowledged that service users will not necessarily access the health service closest to their home, for a variety of different reasons (Curtis et al., 2006). As detailed by Curtis (2007) researchers now have access to more sophisticated research tools to examine more closely the complex relationships between where service users live (or work), the mental health services they use, and the 'real' distance travelled to access those services. Future studies of this nature, seeking to explore service utilization in a more sophisticated way, have to potential to provide a greater understanding of the relationship between SES and mental health service use, guiding the decision-making of mental health planners and policymakers.

\section{CONCLUSION}

For the future we need a greater understanding of the relationship between social conditions and mental health service use, for two main reasons: Firstly, there is an urgent need to improve equity in the accessibility and utilization of mental health services in the less developed countries as well as in the developed ones. In countries with a well developed welfare state, like the UK and Italy, equality was until recently considered to be the equal distribution of services to every individual. However, this principle does not take into account differences between individuals, such as their SES, variations in the social and physical environment in which they live and their capability to access the health services available to them. So, even if services are equally distributed within a community, it does not necessarily follow that equality in access and use of those services is being achieved. Only when we have a clearer understanding of how the social and physical characteristics of different communities shape the 'real' needs for health care, can we achieve equality in mental health care provision.

Secondly, we know that the allocation of economic resources in psychiatry is a complex issue, due largely to the high variability in individual costs of care. All the 
studies that have attempted to forecast the costs of mental health care, using clinical and individual variables, have failed to reach a defined set of predictor variables (Jones et al., in press). It seems plausible therefore, that the inclusion of ecological measures in predictive models, such as socio-economic status and the geographical characteristics of areas where service users live, could improve the explanation of the variation in psychiatric costs. Our view is that this will be an important step forward in providing high quality and effective communitybased mental health services.

\section{REFERENCES}

Amaddeo F. \& Tansella M. (2006). Urbanicity and schizophrenia. From statistical association to causality? Epidemiologia e Psichiatria Sociale 15, 239-241.

Benach J., Yasui Y., Borrell C., Saez M. \& Pasarin M.I. (2001). Material deprivation and leading causes of death by gender: evidence from a nationwide small area study. Journal of Epidemiology and Community Health 55, 239-245.

Bijl R.V., Ravelli A. \& van Z.G. (1998). Prevalence of psychiatric disorder in the general population: results of The Netherlands Mental Health Survey and Incidence Study (NEMESIS). Social Psychiatry and Psychiatric Epidemiology 33, 587-595.

Blazer D.G., Landerman L.R., Fillenbaum G. \& Horner R. (1995). Health services access and use among older adults in North Carolina: urban vs rural residents. American Journal of Public Health 85, 1384-1390.

Boardman A.P., Hodgson R.E., Lewis M. \& Allen K. (1997). Social indicators and the prediction of psychiatric admission in different diagnostic groups. British Journal of Psychiatry 171, 457-462.

Bonizzato P. \& Tello J.E. (2003). Socio-economic inequalities and mental health. I. Concepts, theories, and interpretations. Epidemiologia e Psichiatria Sociale 12, 205-218.

Cadum E., Costa G., Biggeri A. \& Martuzzi M. (1999). Deprivation and mortality: a deprivation index suitable for geographical analysis of inequalities. Epidemiologia e Prevenzione 23, 175-187.

Carstairs V. \& Morris R. (1991). Deprivation and Health in Scotland., Aberdeen University Press: Aberdeen.

Curtis S., Almog M., Congdon P. \& Ellerman R. (2006). County variation in the use of inpatient and ambulatory care in New York State. Paper presented at the Association of American Geographers Annual Conference, March 2006, Chicago, USA.

Curtis S. (2007) Socio-economic status and geographies of psychiatric inpatient service use; places, provision, power and wellbeing. Epidemiologia e Psichiatria Sociale 16, 10-15.

Dohrenwend B.P. (1990). Socioeconomic status (SES) and psychiatric disorders. Are the issues still compelling? Social Psychiatry and Psychiatric Epidemiology 25, 41-47.

Faris R.E.L. \& Dunham H.W. (1939). Mental Disorders in Urban Areas: an Ecological Study of Schizophrenia and other Psychose., University of Chicago Press: Chicago.

Glover G.R., Leese M. \& McCrone P. (1999). More severe mental illness is more concentrated in deprived areas. British Journal of Psychiatry 175, 544-548.

Harrison J., Barrow S. \& Creed F. (1995). Social deprivation and psychiatric admission rates among different diagnostic groups. British Journal of Psychiatry 167, 456-462.

Haynes R., Bentham G., Lovett A. \& Gale S. (1999). Effects of distances to hospital and GP surgery on hospital inpatient episodes, controlling for needs and provision. Social Science and Medicine 49, 425-433.

Jarman B. (1983). Identification of underprivileged areas. British Medical Journal (Clinical Research Edition) 286, 1705-1709.

Jarman B., Hirsch S., White P. \& Driscoll R. (1992). Predicting psychiatric admission rates. British Medical Journal 304, 1146-1151.

Jones, J., Amaddeo, F., Barbui, C. \& Tansella, M. (in press). Predicting costs of mental health care: A critical literature review. Psychological Medicine.

Joseph A.E. \& Philips D.R. (1984). Accessibility and Utilization: Geographical Perspectives on Health Care Delivery. Harper and Row: New York.

Koppel S. \& McGuffin P. (1999). Socio-economic factors that predict psychiatric admissions at a local level. Psychological Medicine 29, 1235-1241.

Lovett A., Haynes R., Sunnenberg G. \& Gale S. (2002). Car travel time and accessibility by bus to general practitioner services: a study using patient registers and GIS. Social Science and Medicine 55, 97-111.

McGrath J. \& Scott J. (2006). Urban birth and risk of schizophrenia: a worrying example of epidemiology where the data are stronger than the hypotheses. Epidemiologia e Psichiatria Sociale 15, 243-246.

Michelozzi P., Perucci C.A., Forastiere F., Fusco D., Ancona C. \& Dell'Orco V. (1999). Inequality in health: socioeconomic differentials in mortality in Rome, 1990-95. Journal of Epidemiology and Community Health 53, 687-693.

NHS Centre for Reviews and Dissemination (1997). Concentration and Choice in the Provision of Hospital Services. The Relationship between Concentration, Patient Accessibility and Utilisation of Services (part III). University of York: York.

Ostler K., Thompson C., Kinmonth A.L., Peveler R.C., Stevens L. \& Stevens A. (2001). Influence of socio-economic deprivation on the prevalence and outcome of depression in primary care: the Hampshire Depression Project. British Journal of Psychiatry 178, 12-17.

Pedersen C.B. \& Mortensen P.B. (2006). Why factors rooted in the family may solely explain the urban-rural differences in schizophrenia risk estimates. Epidemiologia e Psichiatria Sociale 15, 247-251.

Regione Toscana (2001). SLTo (Studio Longitudinale Toscano). Condizione Socio-Economica e Mortalità in Toscana. Informazioni Statistiche. Edizioni Regione Toscana: Firenze.

Sen A. (1992) Inequality Reexamined. Oxford University Press: Oxford.

Spauwen J. \& van Os J. (2006). The psychosis proneness: psychosis persistence model as an explanation for the association between urbanicity and psychosis. Epidemiologia e Psichiatria Sociale 15, 252-257.

Tansella M., Bisoffi G. \& Thornicroft G. (1993). Are social deprivation and psychiatric service utilisation associated in neurotic disorders? A case register study in south Verona. Social Psychiatry and Psychiatric Epidemiology 28, 225-230.

Tello J.E., Mazzi M., Tansella M., Bonizzato P., Jones J. \& Amaddeo F. (2005). Does socioeconomic status affect the use of communitybased psychiatric services? A South Verona case register study. Acta Psychiatrica Scandinavica 112, 215-223.

Thornicroft G. (1991). Social deprivation and rates of treated mental disorder. Developing statistical models to predict psychiatric service utilisation. British Journal of Psychiatry 158, 475-484.

Thornicroft G., Bisoffi G., De Salvia D. \& Tansella M. (1993). Urbanrural differences in the associations between social deprivation and psychiatric service utilization in schizophrenia and all diagnoses: a case-register study in Northern Italy. Psychological Medicine 23, 487-496.

Townsend, P. (1987). Deprivation. Journal of Social Policy 16, 125-146.

Weich S., Lewis G. \& Jenkins S.P. (2001). Income inequality and the prevalence of common mental disorders in Britain. British Journal of Psychiatry 178, 222-227.

World Health Organisation (2001) The World Health Report 2001. Mental Health: New Understanding, New Hope. World Health Organisation: Geneva. 